doi: 10.15503.jecs2021.2.505.526

Journal of Education Culture and Society No. 2_2021

\title{
EUROPEAN CULTURAL HERITAGE AND SKILLS DEVELOPMENT COURSE FOR ADULT LEARNERS' SELF-DEVELOPMENT
}

\author{
INETA LUKA \\ Turiba University, Department of Languages \\ Graudu 68, Riga, LV-1058, Latvia \\ E-mail address: ineta@turiba.lv \\ ORCID: https://orcid.org/0000-0003-4706-1663
}

\begin{abstract}
Aim. This article aims to evaluate the target course created and the development of adult learners' $21^{\text {st }}$ century skills during the course implementation in six EU countries.

Concept. European Cultural Heritage and Skills Development Course is a culture-based blended-learning course created within the framework of the Erasmus+ project "Cultural Knowledge and Language Competences as a Means to Develop $21^{\text {st }}$ Century Skills" conducted in six EU countries: Croatia, Latvia, Slovenia, Romania, Poland and Czech Republic (Project No. 2018-1-HR-01-KA204-047430; 20182021). The course content is presented in a form of a story, applying innovative methodologies and tools increasing adult learners' cultural knowledge and ensuring the skills development. This article focusses on blended-learning in particular, and the course evaluation given by learners and teachers after the course implementation in the six partner countries as well as the development of adult learners' $21^{\text {st }}$ century skills.

Results and conclusion. The results indicate a positive evaluation of the learning platform, the learning methodologies and tasks as well as a positive trend considering the development of learners' $21^{\text {st }}$ century skills, including the English language competences. Although the results varied from country to country, no extremely significant differences between the evaluation done by learners and the teachers were found, thus the course may be applicable to adult teaching/learning.

Practical application. The created blended-learning course may be a viable option for developing adult learners' $21^{\text {st }}$ century skills and increasing their cultural awareness of the less known EU intangible cultural heritage.

Originality. The contribution describes the difference between flipped, hybrid and blended-learning and introduces a novel approach of creating a blended-learning course for adult learners.
\end{abstract}

Key words: blended-learning, learning platform, language competence, $21^{\text {st }}$ century skills, cultural awareness 


\section{INTRODUCTION}

A ccording to UNESCO (2021a), over 1.5 billion learners, which constitutes demic at the peak of the crisis. Furthermore, "for most countries, the pandemic has challenged education systems and speeded up digital transformation. New methodologies and approaches were required: adequate infrastructure, access to connectivity, devices, digital platforms, appropriate learning resources and adequate digital skills" (UNESCO, 2021b, p. 12). The given situation highlighted the importance of distance learning in which teaching/learning is implemented through online technologies (El Refae et al., 2021). In fact, e-learning is not a recent invention. It originated with the spread of the Internet in the 1990s (Ismaili, 2021). However, during the pandemic, e-learning gained its momentum and became mandatory. Furthermore, e-learning has turned out to be the only viable option for implementing the study process, including adult learning. Various online courses, many of them applying an online or a blended-learning format, have been created worldwide which may successfully be implemented in adult learning currently.

One of such courses - European Cultural Heritage and Skills Development Course - has been created within the framework of the Erasmus+ project "Cultural Knowledge and Language Competences as a Means to Develop $21^{\text {st }}$ Century Skills" conducted in six EU countries: Croatia, Latvia, Slovenia, Romania, Poland and the Czech Republic (Project No.2018-1-HR-01-KA204-047430; 2018-2021). The aim of the project is to develop adult learners' relevant $21^{\text {st }}$ century skills (problem solving, communication, collaboration, creativity, innovation, initiative, digital skills, etc.), language and intercultural competences and foster learners' knowledge of the rich European cultural heritage and its values by applying innovative learning approaches and materials. Consequently, this will enable increasing learners' education level and will bring them closer to their cultural heritage, history and the common European values, as well as enhance their overall development and employability. The target audience is adult learners, including those with certain barriers to learning (geographic, economic, cultural, social or educational ones). The aim of the given blended-learning course is to increase adult learners' awareness on the rich European cultural heritage and enhance the development of learners' 21st century skills, simultaneously fostering learners' English language competence.

Content and Language Integrated Learning (CLIL) methodology has been applied to educate people on the rich cultural heritage of the partner countries, thus raising learners' cultural awareness, and developing their $21^{\text {st }}$ century skills via a medium of English, a significant foreign language in the partner countries. The course comprises 18 modules, the content of which is presented in a form of a story/script, applying innovative methodologies and tools (webquests, case studies, vialogues, videos, audiorecordings, design thinking tools, interactive games, etc.) increasing learners' cultural knowledge and ensuring the skills development. The topics are versatile, which enabled cre- 
ating various kinds of tasks: reading, listening, audio, video, speaking, interactive games, face-to-face, etc.

The article "Creating a culture-based language learning course for developing adult learners' 21st century skills" published in the Journal of Education Culture and Society of 2019, Vol. 10, No.2. (Luka, 2019) introduces the course creation, the adult learning theories, gives an insight in all course methodologies applied. Hence, this article focuses on blended- learning in particular, and the course evaluation given by learners and teachers after the course implementation in the six partner countries as wellas the development of adult learners' $21^{\text {st }}$ century skills.

\section{THEORETICAL FRAMEWORK}

The term blended-learning is not new. According to previous research (Güzer \& Caner, 2014, p. 4596), it became "one of the most popular pedagogical concepts at the beginning of 2000." Thanks to technological possibilities and spread of the Internet, it originated as an alternative to traditional face-to-face teaching/learning. However, some authors have traced the origin of blended learning even before 2000, e.g., Norm Friesen (2012) mentions a news release by EPICLearning, an Atlanta-based software company, advertising their courses using a blended-learning approach in 1999 and Ray Archee (2015) explains her experience of creating first blended-learning courses in 1996.

Since 2000, a novel trend of mixing online learning with traditional face-to-face learning has originated. Literature mentions several terminology items - blended-learning, hybrid learning, flipped learning (Rasheed et al., 2020). However, these are not synonymous notions. The difference lies in "the sequence of integrating face-to-face and online sessions" (Rasheed et al., 2020, p. 1).

Flipped learning became especially popular after 2013 and it has been used in teaching/learning of various subjects in the fields of social sciences, IT, engineering, medicine, mathematics, arts and humanities, business and management. According to the statistics of SCOPUS articles published, the USA, China, Taiwan, Australia and South Korea are the top five countries applying flipped learning (Hwang et al., 2019). Flipped learning, also known as inverted learning or reverse teaching, implies that learners first acquire the content online at home and afterwards, in class sessions, learners and teachers collaboratively do tasks and solve the problems (Arnold-Garza, 2014). This involves autonomous learning while doing home tasks and then strengthening the knowledge acquired and the skills developed in face-to-face sessions. One of the most popular flipped learning definitions postulates that it is a

pedagogical approach in which direct instruction moves from the group learning space to the individual learning space, and the resulting group space is transformed into a dynamic, interactive learning environment where the educator guides students as they apply concepts and engage creatively in the subject matter. (Flipped Learning Network [FLN], 2014, p.1) 
Consequently, students have more time and opportunities for interaction with group mates and a teacher and this furthers the development of higher order thinking skills (Hwang et al., 2019) and, as claimed by Rosemary Fisher et al. (2020), by engaging learners in mutual collaboration, flipped learning contributes to attaining students' learning outcomes.

Although in many studies, especially those conducted prior to the Covid-19 pandemic, the two notions blended-learning and hybrid learning have been used interchangeably, more in-depth research of the terminology shows another use of the term hybrid learning. Hybrid learning has been defined as "an educational model where some students attend class in-person, while others join the class virtually from home. Educators teach remote and in-person students at the same time using tools like video conferencing hardware and software" (Boyarsky, 2020). The main difference from blended-learning lies in the fact that a teacher teaches both kind of students synchronously - the one sat home and those in the classroom, whereas in blended-learning these are two distinct stages implemented one after the other. Nevertheless, hybrid learning may also involve some asynchronous work when all students are working individually remotely on assignments. According to Ebba Ossiannilsson (2016), blendedlearning describes a consecutive process, whereas hybrid learning approach deals with a series of various practices that are implemented at the same time.

Although currently the world knows hybrid learning because of implementing the education process remotely and in a hybrid format due to the Covid-19 pandemic, previously the hybrid learning mode was applied to implement learning in two different environments simultaneously, e.g., when merging learning and work processes in situated learning environments (Zitter \& Hoeve, 2012) and implementing "multi-campus learning and inter-institutional collaboration by connecting remote groups with the traditional face-toface classrooms" (Raes et al., 2020, p. 269) as a part of a study programme or a virtual conference.

Blended-learning became especially popular during the last twenty years when due to the globalisation trends, an increase of student numbers internationally, implementation of educational offer all the year round and other reasons, educational institutions started to apply blended-learning approach for e-learning courses or introduced a part of blended-learning elements in their regular courses (Hubackova, 2015). However, blended-learning and e-learning cannot be considered as synonymous notions.

Helena Rodrigues et al. (2019, p. 95) claim that e-learning is "an innovative web-based system based on digital technologies and other forms of educational materials whose primary goal is to provide students with a personalised, learner-centred, open, enjoyable, and interactive learning environment supporting and enhancing the learning processes," whereas blended-learning combines two different forms of learning (classroom and web-based) applying various web-based technologies (online study materials, online textbooks, blogs, chat rooms, etc.) and traditional face-to-face materials. The combination of web-based and face-to-face stages depends on the course content, teach- 
er's experience, the learning goals and outcomes to be attained as well as the target groups (Koşar, 2016). Moreover, an essential characteristic of a blendedlearning course is its scope of instruction provided online. Traditionally, in blended-learning courses, the online teaching/learning part shall constitute $30-79 \%$ of the total scope of the course (Allen et al., 2007). The main advantage of blended-learning lies in the fact that it provides "realistic practical opportunities for learners and teachers to make learning independent, useful, sustainable and ever growing" (Šafranj, 2013, p. 514).

Blended learning has become an umbrella term to describe modern education that makes use of the advantages of using online technologies in the learning process (Hrastinski, 2019) and since technologies are changing, blendedlearning is changing rapidly as well (Prokhorets et al., 2015). Furthermore, the Covid-19 pandemic introduced changes to language teaching/learning and online learning has replaced the face-to-face one (MacIntyre et al., 2020). In the blended-learning context, this means that face-to-face stage shall be implemented in an online mode using various learning platforms and other technological means, instead of real-class meetings.

\section{METHODOLOGY}

The aim of the study is to evaluate the target course created and the development of adult learners' $21^{\text {st }}$ century skills during the course implementation in six European Union countries.

Research question: Can the target course be used to successfully develop learners' $21^{\text {st }}$ century skills and what improvements are required therein?

Research design: the research applies interpretivism paradigm that is "associated with a pluralistic ontological position and an epistemology which believes that building knowledge involves 'interactions' or 'transactions' with the environment" (Dewey, 1929/1988, p. 160), emphasising the importance of the research context, and the effectiveness of intervention in problem solving (O'Hanlon, 2019). Concurrent mixed-methods research design has been chosen as the application of both the quantitative and qualitative approaches to the research ensures obtaining a more complete and precise data on the research object (O'Hanlon, 2019).

Research sample: the study involves two purposeful samples. In total, 227 adult learners and 10 English teachers from the six partner countries:

- Learners' profile: 40 from Croatia, 32 - Czech Republic, 33 - Latvia, 31 Poland, 35 - Romania, 56 - Slovenia. Their English language level: B2 (47\%), C1 (25\%), B1 (22\%). 73 learners (32\%) were aged 15-19, 110 learners (49\%) - aged 20-24, 11 learners (5\%) - aged 25-29, 11 learners (5\%) - aged 30-34 and 22 learners (9\%) were 35 and older.

- Teachers' profile: 5 hold a PhD degree, 4 have an MA degree, 1 -BA degree. Their teaching experience was from 7 to 32 years. One was a teacher of IT and the rest were language teachers on daily basis teaching English for 
Special Purposes, English for Academic Purposes, General English and other courses. All of them were experienced adult educators teaching adult students, teachers, seniors, the unemployed, etc.

Research methods: 1) data collection - learners' survey (closed and open questions), learners' unstructured observations done by teachers and structured interviews with teachers, 2) mixed-methods data analysis strategies data transformation and data comparison (O'Hanlon, 2019). Qualitative data was analysed by applying the constant comparative method which is typically used ininterpretivism paradigm (Thomas, 2009). In turn, to find out similarities and differences between learners and teachers' results, quantitative data was analysed conducting descriptive and inferential statistics tests by Statistical Package for the Social Sciences (SPSS).

Research process: The European Cultural Heritage and Skills Development Course contained 18 modules. Each learner studied one module ( 20-30-hour input) independently and in class sessions from February to April 2019. Teachers monitored the process and ensured support during the whole study process. 242 learners from six countries - Croatia, Czech Republic, Latvia, Poland, Romania and Slovenia started the course, but 227 completed it. The reasons for dropping out were illness, change of university, conflicting work schedules or not sufficient English language competence level. After the course completion learners filled in a face-to-face paper-based feedback questionnaire (40 5-point Likert-scale questions, three open essay-type questions, socio-demographic profile), which, as claimed by Peter Tymms (2017), is typically used to ensure quality assurance in higher education institutions, thus it may be applied to adult education as well. Teachers observed learners during all the study process and took notes on each learner's progress (learner's success, problems, overall comments, final evaluation) and filled-in the evaluation form (27 5-point Likert-scale questions, one open question, socio-demographic profile).

\section{FINDINGS AND DISCUSSION}

The results section will present the findings in three categories: 1) evaluation of the learning platform; 2) evaluation of the course methodologies and tasks; 3) evaluation of the learners' skills development.

\section{Platform evaluation}

Both learners and teachers positively evaluated the learning platform. The means given by the learners ranged from 3.7621 to 4.0661 (mode=4.00) and evaluation by the teachers was even higher: from 4.0000 to 4.5556 (modes 4.00 and 5.00). The data comparison of the six same type variables is shown in Fig. 1. The highest evaluation is given to the usefulness of the learning platform, its interesting design and content as well as to the interactivity and creativity of the learning platform. 


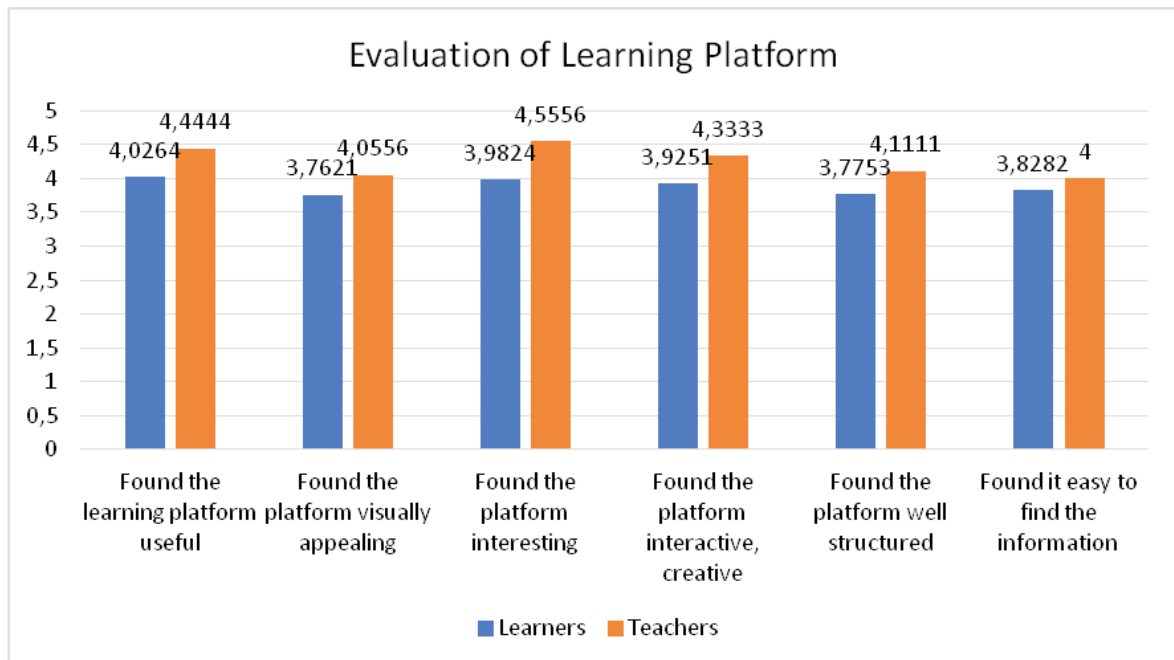

Fig. 1.Comparative evaluation of learning platform, means

Source: own research based on the learners' and teachers' feedback.

As it is seen from Fig. 1, the teachers evaluated the learning platform slightly higher than the learners. Comparing the results of both groups learners and teachers, significant differences were discovered for the variables found the platform useful (Asymp.Sig.2-tailed=0.029) and found the platform interesting (Asymp.Sig.2-tailed=0.003). Conducting an analysis by the country, significant differences were discovered for the same variables as well, wherein the evaluation was as follows: found the platform useful (Asymp.Sig.2-tailed $=0.000$ ) and found the platform interesting (Asymp.Sig.2-tailed=0.005). Considering the usefulness of the platform, Czech and Romanian learners and teachers have given a higher evaluation than other partners (151.40 for Czech Republic and 149.00 for Romania) and the Polish respondents have given the lowest evaluation (Mean Rank 89.81). This may be explained by the target audience as Czech learners were students from evening classes and such platforms tend to be suitable for autonomous learning and Romanian learners were students of philology who were used to applying various translation software during studies, but the target audience of the Polish partner was elderly learners requiring special education treatment and consequently they would need more support given by the teacher. Furthermore, Latvian learners found the learning platform more interesting than other learners (Mean Rank 143.86) which may be explained with the target group as well - international students, mostly from Asian countries, studying in Latvia for about half a year, so naturally they were eager to learn more about European culture.

Teachers' feedback questionnaire contained one more variable found it easy to explain it to the learners which they evaluated highly, mean 4.3889 and mode 5.00, whereas learners' feedback questionnaire included 4 other variables: 
- It took me too long to understand how the platform works (mean 2.3921; mode $=2.00$ ) and since this is a reverse question, the feedback is positive;

- It was easy to understand how to do the tasks (mean 4.0661, mode 4.00), wherein 102 learners agreed and 83 learners strongly agreed with the statement;

- It was easy to understand the result (mean 4.0617, mode 4.00), wherein 90 learners agreed and 85 learners strongly agreed with the statement;

- The learner will suggest the platform to other learners (mean 3.9207, mode 4.00), wherein 91 learners agreed and 69 learners strongly agreed with this statement but 51 were neutral, which lowered the mean value of the score.

Qualitative data from the learners' survey confirm the quantitative dataand also point to certain challenges connected with the learning platform.

Several learners have emphasised that the platform was "creative, interactive and well structured" (Learner 76 from Latvia), "creative and well understandable" (Learner 158 from Romania) and "it was easy to learn as the platform was interactive and interesting" (Learner 160 from Romania). They also liked "the way of presenting visuals" and found "useful information" (Learner 98 from Latvia). Learners liked that they were encouraged to do some research on their own -"I like that the platform encouraged us to use other sources of information from the Internet, and that the platform uses various kinds of media (blogs, videos)" (Learner 140 from Romania) and they admitted that "the creators of the learning platform did a good job. They put a lot of information and interesting and interactive tasks" (Learner 73 from Latvia).

The qualitative data from teachers' observations of learners, similarly to the qualitative data obtained in the learners' survey, confirm the quantitative findings. The teacher from Croatia has marked that her student "liked the platform and its design. She thinks it's an interesting way to learn about cultural heritage and it is useful as well" (Learner 10 from Croatia, doing Module 3 of Czech Republic). This observation is similar to the information obtained in the learners' questionnaire. Another similarity concerns learners' positive feelings about doing additional search on the Internet that enables developing not only language skills but also the digital ones. The teacher from Romania remarks that the learner said that "she liked using her computer for learning and surfing the Internet and she found the information and tasks useful. It was a happy moment to see her so busy solving the tasks and speaking about the information she found" (Learner 11 from Romania doing Module 2 of Latvia).

These findings are in line with the cognitions from the theory on the significance of technology applied, namely the design and functionality of the learning platform. Bayram Güzer and Hamit Caner (2014) emphasise the role of technological innovations in teaching/learning. The authors claim that although new models of blending will emerge, the key issue will remain the same $3 / 4$ how to organise the learning environment so that learners could attain learning outcomes in the best way. Their suggestion is to base learning on constructivist and collaborative grounds. Thus, the learning platform has to be visually appealing, simple and easy to understand also when learners are collaborating on a task independently. 
As mentioned above, both learners and teachers highlighted some drawbacks as well. Some of them were concerned by technological issues, for example Learner 31 from Croatia admitted that "it took too long time to understand how this platform works," Learner 42 from Czech Republic admitted having "problems with logging in from home. It was quite difficult for me to understand." Other kind of problems were connected with instructions which were not written very clearly for some tasks (Learner 100 from Latvia). The teacher from Latvia made a similar comment: "She has quite good knowledge of general English, but still it took much time to complete the online tasks due to the lack of experience" (Learner 5 from Latvia doing Module 2 of Croatia).

This emphasises the significance of methodological support, which, according to Dmitry Matukhin and Elena Zhitkova (2015, p. 185), has to be created as "a system composed of three subsystems: 1) content; 2) software; 3) methodology." Céline Cocquytet et al. (2019, p. 5-6) also emphasise the need of instructional, transfer, peer and technical support. Instructional support is pedagogical guidance on explaining the tasks, answering learners' questions, and providing meaningful feedback. Transfer support refers to teacher's help provided in facilitating transfer from classroom to a learner's daily life. Peer support stems from learner-learner mutually solving the problems arisen. Technical support is connected with learner-content interaction on the learning platform and technician's interaction, and it ensures learning from one another, and support is crucial for digitally less knowledgeable learners.

Thus, it may be concluded that overall, the platform evaluation is positive, and it may be used for teaching/learning of various groups of adult learners, but each group has to be evaluated separately and support has to be provided in terms of technological aspects (digital skills) and content (language skills and information searching skills).

\section{Evaluation of course methodologies and tasks}

In the course design, CLIL methodology has been applied in order to educate learners about the rich cultural heritage of the partner countries, thus contributing to the increase of their cultural awareness, and enhance the development of adult learners' $21^{\text {st }}$ century skills via a medium of English. As mentioned above, the course is a blended-learning one comprising of online and face-to-face parts. It is formed by 18 comprehensive modules -3 per partner country. The module content is centred round the rich European intangible cultural heritage. To make the course interactive and innovative, various new methodologies such as webquests (combining the material provided for learners on the platform with their own research done on the Internet to solve the task and create the product), case studies (Internet based and face-to-face case studies to stimulate collaboration and problem-solving skills), interactive games (Crosswords, Hangman, Millionaire, Word search), various design thinking tools (visualisation tasks, journey mapping, mind mapping, collabs) (cf. Luka, 2019) have been used for online tasks and the face-to-face stage was implemented both in classroom communication and chat rooms. Another 
innovation is the united story that starts with an introduction - presenting the context of the story, then the situation is elaborated in the main part, and it ends with a problem solution or a provocative question for further analysis. The role of various methodologies is to make the content unique and develop adult learners' $21^{\text {st }}$ century skills while doing the tasks individually and collaborating on finding problem-solutions in pair work or groupwork activities.

A summary of all the modules is included in the course curriculum (Luka, 2018) and the modules are available on the learning platform: http:/ / e-culture. $\mathrm{eu} /$.

Both learners and teachers evaluated the course content and methodologies used in the course. In learners' questionnaire, 22 variables concerned these issues (means=3.2996-4.2115; mode 4.00), whereas in the teachers' feedback form -13 variables dealt with the course content and methodologies (means=3.4444-4.5000; mode 4.00). Therefore, for a comparative analysis, 11 variables of the same type have been selected (see Fig. 2).

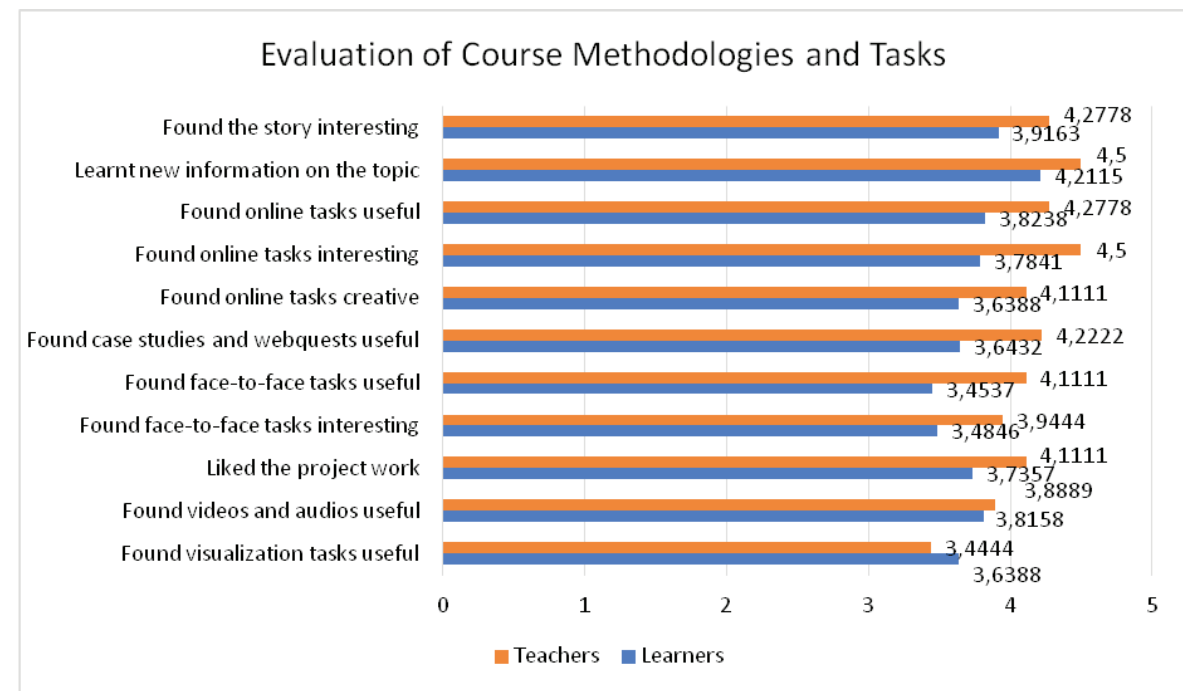

Fig. 2.Comparative evaluation of course methodologies and tasks, means Source: own research based on the learners' and teachers' feedback.

The comparative research shows that, similarly to the platform evaluation, teachers evaluated the course methodologies and tasks higher than the learners. The only exception is usefulness of visualisation tasks, wherein learners have a slightly higher score than the teachers, but the difference is not significant (Asymp.Sig.2-tailed $=0.654>0.05$ ).

Comparing the answers of both groups-learners and teachers, significant differences have been found for 4 variables out of 11: the learner found the online tasks useful (Asymp.Sig.2-tailed=0.029), the learner found the online tasks interesting (Asymp.Sig.2-tailed=0.000), the learner found the case studies and webquests 
useful (Asymp.Sig.2-tailed=0.007), the learner found the face-to-face tasks useful (Asymp.Sig.2-tailed=0.654>0.005). Considering learners and teachers of different countries, significant differences were found for all variables (Asymp. Sig.2-tailed=0.000-0.024) and the Czech learners evaluated the methodologies and tasks higher than other partners, followed by Romania and Latvia. This may be attributed to learners' profile again as the Czech learners were evening students and Romanian and Latvian learners were University students.

Qualitative data analysis was done applying content analysis. 106 learners responded that they liked the course. Three meta-codes were created to analyse their answers: Content, Tasks and Overall liked the module, each of them was categorised into several sub-categories which were further broken down into more detailed groups and sub-groups (see Fig. 3).

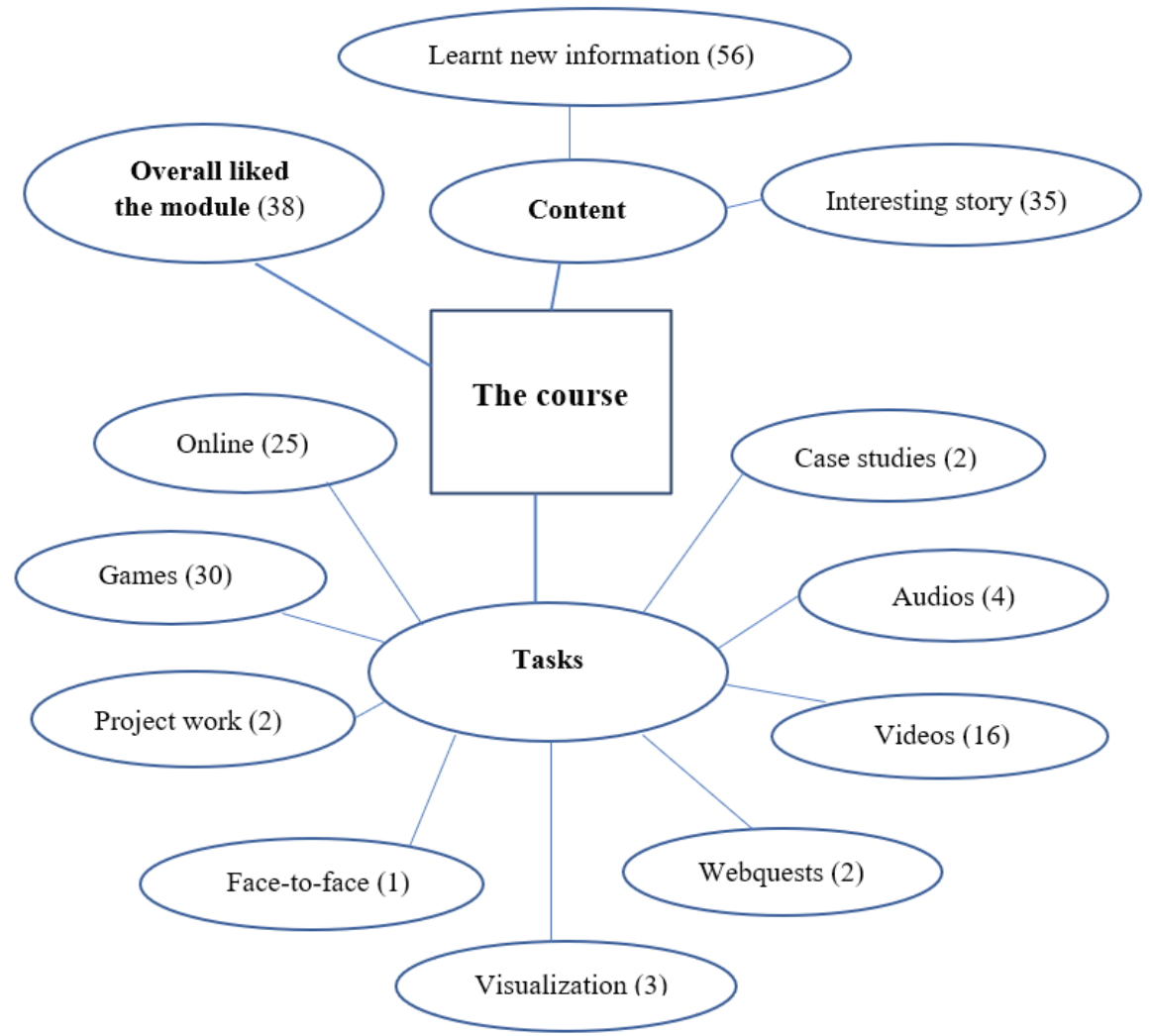

Fig. 3. Coding of learners' expressions on course methodologies and tasks Source: own research based on the learners' feedback.

The number in brackets indicates the first group of keywords coded from open questions. Each group is further subdivided into several sub-groups. Compared to other two meta-codes Content and Tasks which have been subdivided into several sub-levels, meta-code Overall liked the module contains 
only the first level of codes, mostly adjectives describing learners' feelings. The adjectives are mentioned in succession of frequency: creative (7 learners), well structured (5), useful (5), interesting (5), innovative (3), interactive (3). Three learners admitted that they "want to do more modules" and three "will suggest the course to other learners," additionally two learners appreciated "variety of tasks" and two learners found it "an attractive way of teaching." These data coincide with teachers' observations of learners. Below are some examples to support this claim:

- "She liked the module and the concept of learning a language through getting to know a culture" (Learner 7 from Romania doing Module 3 of Slovenia);

- "The learner found the module very exciting, in spite of the fact that he considers that it did not develop his creativity" (Learner 1 from Romania doing Module 2 of Slovenia);

- "She claims the course to be an interesting form of learning languages and about other cultures" (Learner 2 of Czech Republic doing Module 3 of Latvia).

Considering the meta-code Content, two sub-categories could be singled out: 1) "Learnt new information about the country" mentioned 56 times and further broken down into 11 groups and 2) "Interesting story" mentioned 35 times and broken down into 8 groups (see Table 1).

Table 1

Content codes from learners' open questions

Sub-categories

Groups

Sub-groups

Learnt new information No specific group (8)

about the country (56) Latvia (6)

Walking sticks (1)

Latvian song and dance festival

(1)

Livonians (1)

\begin{tabular}{ll}
\hline Czech Republic (4) & Interesting facts (1) \\
\hline Authentic texts (1) & \\
\hline Useful information (3) & \\
\hline \multicolumn{2}{l}{ Traditions and customs (5) } \\
\hline New culture (9) \\
\hline Food (1) \\
\hline A lot (1) \\
\hline Poland (8) Christmas traditions and dishes
\end{tabular}

(5)

Nice places (1)

Croatia (8) Dubrovnik (2)

Horses (2) 


\begin{tabular}{lll}
\multicolumn{1}{c}{ Sub-categories } & \multicolumn{1}{c}{ Groups } & \multicolumn{1}{c}{ Sub-groups } \\
\hline Interesting story (35) & No specific group (24) & \\
\cline { 2 - 3 } & Creative (2) & \\
\cline { 2 - 3 } Fascinating (1) & Christmas traditions (1) \\
\cline { 2 - 3 } Useful (1) & Woland (1) & Walking sticks (1) \\
\cline { 2 - 3 } Czech Republic (1) & Traditions and celebrations (1) \\
\hline & Latvia (2) & History and traditions (1) \\
\cline { 2 - 2 } & Croatia (1) &
\end{tabular}

(2)

Source: own research based on learners' feedback.

The teachers mostly focused on describing learners' skills and how they did the tasks than learners' overall emotions, but those who noticed learners' emotions described them as positive. For example, the English teacher from Romania characterising the attitude of Learner 12 while doing Module 2 of Latvia said:

The biggest success for her was that she was the only one in the group who knew what the UNESCO abbreviation is. She was interested in doing the tasks and even finding out more about her own cultural heritage. She learnt not only new vocabulary but more information about our own cultural heritage.

These findings are similar to the ones obtained in other researches on blended-learning concerning the way of finding previously unknown information and its presentation. For example, the research conducted in Japan involving 61 learners (Miyazoe \& Anderson, 2012) showed that learners associated blended-learning with novelty and fun and enjoyed the use of various forums, blogs and wikis in learning the English language.

The main function of any language is communication and language teaching methodologies in a form of specifically tailored tasks are crucial in developing learners' functional communication skills. As highlighted by Blanka Frydrychova Klimova and Jaroslav Kacetl (2015), online learning provides an access to target language culture through various authentic videos and audios, collaboration in chat rooms and forums which enables language learners use authentic materials in doing the tasks and interact and collaborate with a teacher, group mates and even with language learners of other institutions. The tasks have to be interesting, useful and interactive so that they could stimulate language learning.

The third meta-code Tasks had the largest number of sub-categories (9 subcategories) which were further sub-divided into groups and even sub-groups (see Table 2). 
Table 2

Codes for the meta-code "tasks" from learners' open questions

\begin{tabular}{|c|c|c|}
\hline Sub-categories & Groups & Sub-groups \\
\hline \multirow[t]{2}{*}{ Liked audios (4) } & \multicolumn{2}{|l|}{ No specific group (2) } \\
\hline & \multicolumn{2}{|l|}{$\begin{array}{l}\text { Songs (1) } \\
\text { Klapa songs (1) }\end{array}$} \\
\hline \multirow[t]{5}{*}{ Liked videos (16) } & \multicolumn{2}{|l|}{ No specific group (3) } \\
\hline & \multirow[t]{2}{*}{ Learnt new information (8) } & Slovenian Lipizan horses (4) \\
\hline & & Latvian walking sticks (2) \\
\hline & \multicolumn{2}{|l|}{ Interesting (4) } \\
\hline & \multicolumn{2}{|l|}{ Visually appealing (1) } \\
\hline Webquests (2) & Searching for information (2) & $\begin{array}{l}\text { New information (1) } \\
\text { About museums (1) }\end{array}$ \\
\hline \multirow[t]{7}{*}{ Online tasks (25) } & \multicolumn{2}{|l|}{ No specific group (3) } \\
\hline & Interesting (5) & $\begin{array}{l}\text { Reading (1) } \\
\text { Listening (1) }\end{array}$ \\
\hline & Creative (3) & \\
\hline & Interactive (2) & \\
\hline & Easy to understand (1) & \\
\hline & Drag and drop (1) & \\
\hline & Useful (10) & $\begin{array}{l}\text { Writing (2) } \\
\text { Reading (3) } \\
\text { Gap fil (1) } \\
\text { Listening (5) } \\
\text { Vocabulary(2) } \\
\text { Learners will like them (1) }\end{array}$ \\
\hline
\end{tabular}

\begin{tabular}{lll}
\hline Visualisation (3) & \multicolumn{2}{l}{ No specific group (1) } \\
\cline { 2 - 3 } & Matching pictures (1) \\
\cline { 2 - 3 } $\begin{array}{l}\text { Finding the way on the map } \\
(1)\end{array}$ & \\
\hline Interactive games (30) & No specific group (15) & Interesting (2) \\
\cline { 2 - 3 } & Crossword (9) & Entertaining (1) \\
& & Glossary for games (1) \\
\cline { 2 - 3 } & Hangman (2) & Interesting (1) $(1)$ \\
\cline { 2 - 3 } & Cryptex (1) & Interesting (1) \\
\cline { 2 - 3 } & Millionaire (2) & Interesting (1) \\
\cline { 2 - 2 } & Interactive (1) \\
\hline
\end{tabular}




\begin{tabular}{|c|c|c|}
\hline Sub-categories & Groups & Sub-groups \\
\hline Face-to-face (1) & Pairwork (1) & \\
\hline Project work (2) & $\begin{array}{l}\text { Learnt new information (1) } \\
\text { Gained new experience (1) }\end{array}$ & \\
\hline Case studies (2) & $\begin{array}{l}\text { No specific group (1) } \\
\text { Interesting (1) }\end{array}$ & \\
\hline
\end{tabular}

Source: own research based on learners' feedback.

In their answers, students indicated which type of tasks they specifically liked. As it can be seen from Table 2, learners especially liked interactive games, online tasks and video tasks. The teachers observed the same. Below are some quotations to illustrate this:

- "She found the tasks interesting and enjoyed teamwork" (English teacher from Romania about Learner 5 doing Module 2 of Latvia);

- "The student enjoyed doing both the online and the project work, because both were motivating to find new information" (English teacher from Romania about Learner 3 doing Module 2 of Slovenia);

- "The learner enjoyed learning new information on Latvia. This student enjoyed writing the dialogues and was very creative during his work. He found the course well-structured and easily followed the class activities. Audio and video tasks were most interesting to his mind" (English teacher from Poland about Learner 8 doing Module 1 of Latvia);

- "She liked the Hangman and Millionaire game and she added that was a great chance to learn something new about the Czech Republic" (English teacher from Croatia about Learner 7 doing Module 3 of Czech Republic).

It may be concluded that the target course is created using various types of tasks, applying traditional and novel teaching methodologies and learners enjoyed it. However, it has to be added that teachers evaluated the course higher than learners and differences were observed among different types of learners. In order to eliminate the challenges learners face, methodological support is crucial, and a teacher's constant help is highly recommended, especially for more inexperienced learners and learners having social, cultural and economic barriers to learning as well as those requiring special educational treatment.

Teachers' challenges in the online component of blended learning may be systematised into four groups: 1) teachers' technological literacy and competency challenges; 2 ) online video challenges; 3 ) technological operational challenges; and 4) teachers' belief challenges (Rasheed et al., 2020). Similarly, Sarka Hubackova and Ilona Semradova (2016) pointed to the demanding arrangement of the course content concerning teachers. Moreover, another challenge may be dependence on other technological devices.

In the target project, the teachers' admitted having experienced online video challenges - the challenges connected with creating qualitative videos for online teaching/learning part. They had spent too much time on designing 
the contents of videos for online tasks. However, they also acknowledged that the technical support provided was really helpful therein.

\section{Evaluation of learners' skills development}

After the course acquisition, learners performed their self-evaluation and teachers evaluated the learners' skills developed. Overall, positive evaluation was given, the means ranging from 3.3788 to 3.9603 for learners' self-evaluation and from 3.3333 to 4.5555 for teachers evaluating the learners' skills development (see Fig. 4). Comparing the development of language skills and other $21^{\text {st }}$ century skills, it is apparent that $21^{\text {st }}$ century skills have received a slightly higher evaluation (av. mean=3.6353) than language skills (av. mean=3.6138). But, comparing the evaluation of the skills development given by learners and teachers, both groups evaluated $21^{\text {st }}$ century skills (av. mean $=4.0740$ by teachers and av. mean $=3.6005$ by learners) higher than language skills (av. mean $=3.8333$ by teachers and av. mean=3.5964 by learners). As it is evident, in both categories teachers have evaluated the learners' skills development slightly higher than the learners themselves.

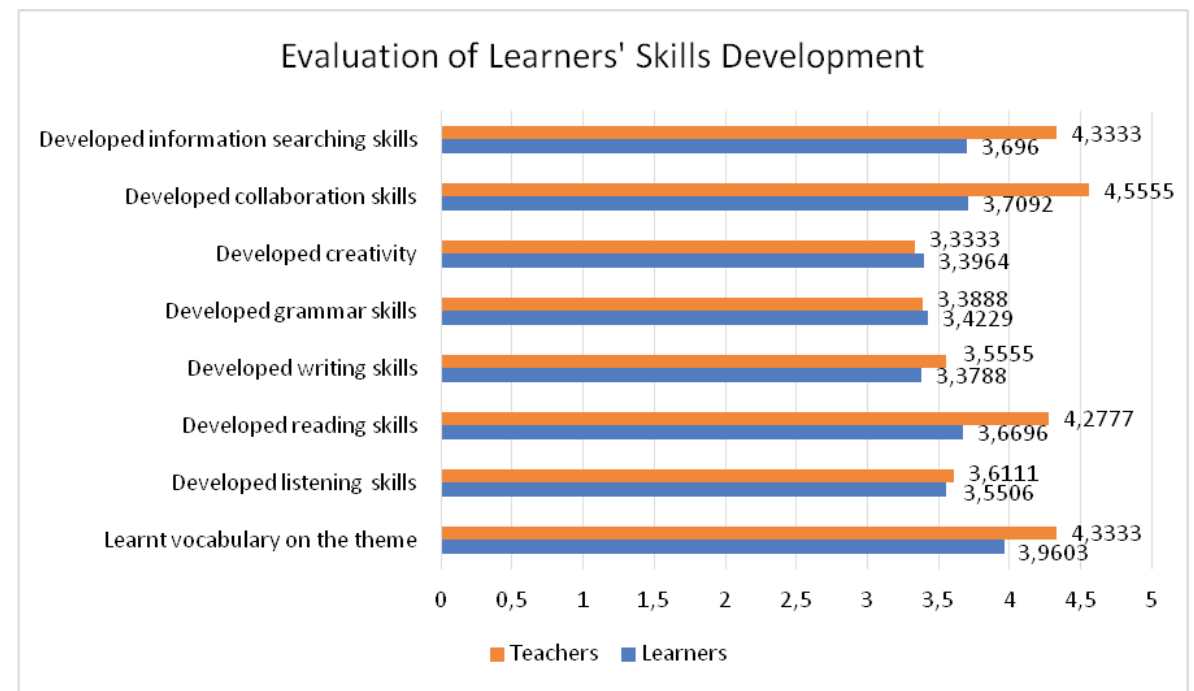

Fig. 4. Comparative evaluation of learners' skills development, means

Source: own research based on the learners' and teachers' feedback.

Although the teachers evaluated the learners' skills development higher than the learners did, significant differences were found only for three skills: reading skills (Asymp.Sig.2-tailed=0.003), collaboration skills (Asymp.Sig.2-tailed=0.000) and information searching skills (Asymp.Sig.2-tailed=0.007). Contrary to these findings, significant differences were found for all the skills as to the partners' country (Asymp.Sig.2-tailed=0.000-0.015). Czech and Romanian learners have developed vocabulary knowledge more than other learners (Mean Ranks 140.30 and 156.51), Latvian learners have developed their 
listening skills (Mean Rank=154.85), reading skills (Mean Rank=158.35) and writing skills (Mean Rank=151.15) higher than other learners. Both Czech and Latvian learners have developed their grammar skills more than other learners (Mean Ranks 152.64 and 161.38). Thus, it may be concluded that the Latvian learners have developed their language skills more than other learners, whereas Polish and Slovenian partners reported a comparatively lower development of learners' language skills than other partners. Concerning other $21^{\text {st }}$ century skills, Slovenian learners demonstrated the highest development of collaboration skills (Mean Rank=146.42), Czech and Latvian participants have developed information searching skills more than other learners (Mean Ranks 151.57 and 153.39) whereas creativity development could be divided into two groups-Croatia, Czech Republic, Latvia and Romania reported its higher development (Mean Ranks from 131.51 to 145.53) than Poland and Slovenia (Mean Ranks 96.21 and 96.14). To summarise, although the results vary, overall, they showed a positive trend in the development of learners' language skills applying the blended-learning approach.

Similarly, previous research has provided evidence that technology-mediated language learning has a positive impact on the development of syntax, vocabulary, speaking and writing skills and intercultural competence (Lai \& $\mathrm{Li}$, 2011). The research conducted by Iliana Lungu (2013) had similar results. Students' self-evaluation test results after the experimental blended-learning course given to a group of twelve adult learners showed that $56.5 \%$ of students admitted having improved their grammatical accuracy, $72 \%$ - vocabulary, $88 \%$ had developed their reading skills and 97\% - listening skills. Furthermore, the research conducted in Japan pointed to the progress in students' writing skills (Miyazoe \& Anderson, 2012) as well as the results of a study of 363 students in Malaysia revealed that $45.56 \%$ reported positive impact of online interaction on their writing task and $44.63 \%$ confirmed the development of their writing skills (Maulan \& Ibrahim, 2012).

However, there are also studies which do not reveal the advantages of blended-learning instruction over face-to-face learning. For example, the results of the research conducted in Turkey with two groups of intermediate English language speakers are in contrast to the current research findings as they demonstrated no improvement in students' vocabulary after the course acquisition (Tosun, 2015).

Considering qualitative data, learners did not share their thoughts on the skills development as much as in the previous categories. 16 answers could be attributed to developing skills, the great majority of them referred to language skills, such as vocabulary (10 learners), two learners admitted having developed listening, reading and writing skills (Learner 79 and Learner 80) and one learner specifically emphasised the development of grammar, reading and writing skills (Learner 135). Learners admitted that "exercises helped to develop various skills" (Learner 157) indicating that this is "an interesting initiative which helps to improve language skills and gain knowledge about other countries" (Learner 128). The combination of learning a language and 
gaining information on the other culture was recognised also by Learner 129 who stressed the "possibility to get to know the culture of other countries and additionally develop one's own language skills and have a nice time while doing the exercises."

Contrary to learners' answers, a vast majority of teachers focussed on the skills development. They acknowledge that learners have developed all language skills, learnt new vocabulary and apart from the language skills, they have improved their collaboration skills, information searching and processing skills, tolerance, an ability to listen to others, an ability to work in a group, as well as analytical thinking skills. They did not evaluate creativity development so much which is evident from the following quotation: "The learner considers that the module did not develop her creativity, but it developed her ability to work in a group" (an English teacher from Romania about Learner 6 doing Module 2 of Slovenia).

To summarise, both quantitative and qualitative data indicate learners' skills development. However, as at the beginning of the course learners were not asked to perform a language test, these evaluation results are based on learners' self-assessment and language teachers' observations done during the course and at the end of the course, therefore, the results indicate a trend and, as seen from the above analysis, it is a positive one.

Moreover, although qualitative data from the current research shows lots of positive comments, 17 learners have also provided their feedback on the problems they faced. These challenges may be attributed to the platform and the tasks mainly. Technical issues concerned not sufficient video quality (Learner 65, Learner 123), photo quality for tasks (Learner 115, Learner 123), uploading the results (Learner 97, Learner 127), not clearly defined task requirements (Learner 33, Learner 70, Learner 75, Learner 85, Learner 88, Learner 127, Learner 129, Learner 130). They did not like that "webquest articles were long and difficult" (Learner 48), tasks were "unclear, not very attractive" (Learner 119). Another student found vocabulary too difficult (Learner 108): "The module was difficult to understand. Unclear, boring and not interesting" (Learner 120). These issues have to be solved to help learners better attain their learning outcomes.

\section{CONCLUSION}

The research results show a positive evaluation of the learning platform, the learning methodologies and tasks as well as a positive trend considering the development of learners' $21^{\text {st }}$ century skills, including the English language competence. Although the results varied from country to country, there were not found extremely significant differences between the evaluation done by learners and the teachers, thus the course may be applicable to adult teaching/learning. However, certain amendments could be required considering target groups of learners - some learners need a lower speed, 
some require more technical assistance, some need more detailed explanations on the tasks to be done. Overall, the course secures attaining its aim develop learners' language competence through contextual modules that provide new information to them on European intangible cultural heritage of the partner countries enhancing their cultural awareness of their own region, country and Europe in general.

To conclude, scholars (Lungu, 2013) postulate that the application of blended-learning courses provides two benefits:

(a) students learn quicker and better through a virtual learning environment (VLE) which is learning flexible, offering them autonomy and self-pacing according to their interests and needs and (b) teachers have more time to do what they do best, i.e., use the rich resources of the classroom to provide interesting lessons. (Lungu, 2013, p. 470)

The author of the current paper definitely disagrees with this claim as the research results showed that teachers have to invest much more work in explaining the material pedagogically and technologically, creating learning materials, adapting them to each learner's learning style and abilities, uploading the materials on the learning platform, etc. However, once the learning platform and the learning course have been created, it is easier to make amendments therein instead of replacing one course book with another and it is definitely more cost effective as well.

Although learners positively evaluated the blended-learning course, the consultancy that might be required $24 / 7$, points to the fact that a teacher is irreplaceable in any language teaching/learning process and a teacher's role in blended-learning and online learning context increases. As pointed out by Fandiño \& Velandia (2020), a teacher has to ensure the academic function providing appropriate learning content and student assessment, technical function - the use of online tools, guiding - managing the course acquisition according to the plan and in the given time period, social - facilitating learners' interaction and motivation, and organisational function-assisting learners with organisational matters.

\section{RESEARCH LIMITATIONS AND IMPLICATIONS FOR FURTHER RESEARCH}

This paper deals with the second stage of the results reflecting learners' and teachers' feedback during and after the European Cultural Heritage and Skills Development Course implementation. During the third stage of the research, a Culture Based Multilingual Blended-learning Language Course for Adult Learners focussing primarily on the development of adult learners' $21^{\text {st }}$ century skills has been created in nine languages and has been implemented in all partner countries. The results obtained during the third stage will be discussed in another article. 


\section{ACKNOWLEDGEMENTS}

The current research has been conducted within the Framework of the Erasmus+ project "Cultural Knowledge and Language Competences as a Means

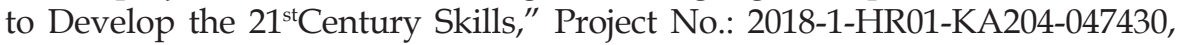
the project period 2018-2021. The project has been funded with the support from the European Commission. This publication reflects the views of the author only, and the Commission cannot be held responsible for any use which may be made of the information contained therein.

The author would like to express her gratitude to the project partners for their contribution in data collection during the course implementation process.

\section{REFERENCES}

[1] Allen, E. I., Seaman, J., \& Garret, R. (2007). Blending in. The extent and promise of blended education in the United States. Needham, MA: Sloan Consortium.

[2] Archee, R. (2015). Is blended learning making us stupid, too? Open Journal of Social Sciences, 3, 65-70. http://dx.doi.org/10.4236/jss.2015.39010.

[3] Arnold-Garza, S. (2014). The flipped classroom teaching model and its use for information literacy instruction. Communications in Information Literacy, 8(1), 7-22. Retrieved May 1, 2021, from https:/ / files.eric.ed.gov/fulltext/EJ1089137.pdf.

[4] Boyarsky, K. (2020). What is hybrid learning? Here's everything you need to know. OwlLabs. Retrieved May 1, 2021, from https://resources.owllabs.com/blog/hybridlearning\#: :text=Hybrid\%20learning\%20is\%20an\%20educational,video\%20conferencing $\% 20$ hardware\%20and \%20software.

[5] Cocquyrt, C., Zhu, C., Diep, A. N., De Greef, M., \& Vanwing, T. (2019). Examining the role of learning support in blended learning foradults' social inclusion and social capital. Computers \& Education,142, Article 103610, 1-19. https:/ / doi.org/10.1016/j.compedu.2019.103610.

[6] Dewey, J. (1988). The quest for certainty. In: J. Boydston (Ed.). The Later Works: 1925-1953, Vol. 4. Carbondale: Southern Illinois University Press. (Original work published in 1929).

[7] El Refae, G. A., Kaba, A., \& Eletter, S. (2021). Distance learning during COVID-19 pandemic: Satisfaction, opportunities and challenges as perceived by faculty members and students. Interactive Technology and Smart Education. https://doi.org/10.1108/ITSE-08-2020-0128.

[8] Fandiño, F. G. E., \& Velandia, A. J. S. (2020). How an online tutor motivates e-learning English. Heliyon,6(e04630), 1-7.https://doi.org/10.1016/j.heliyon.2020.e04630.

[9] Fisher, R. L., LaFerriere, R., \& Rixon, A. (2020). Flipped learning: An effective pedagogy with an Achilles' heel. Innovations in Education and Teaching International, 57(5), 543-554. https:// doi.org/10.1080/14703297.2019.1635904.

[10] FLN. (2014).The four pillars of F-L-I-P. Flipped Learning Network. Retrieved May 3, 2021, fromhttps://flippedlearning.org/wp-content/uploads/2016/07/FLIP_handout_FNL_Web.pdf.

[11] Friesen, N. (2012). Report: Defining blended learning. Retrieved May 3, 2021, fromhttps:/ /www. normfriesen.info/papers/Defining_Blended_Learning_NF.pdf.

[12] Güzer, B., \& Caner, H. (2014). The past, present and future of blended learning: An in-depth analysis of literature. Procedia - Social and Behavioural Sciences, 116, 4596-4603.https://doi. org/10.1016/j.sbspro.2014.01.992.

[13] Hrastinski, S. (2019). What do we mean by blended learning? TechTrends, 63(5), 564-569. https://doi.org/10.1007/s11528-019-00375-5.

[14] Hubackova, S. (2015). Blended learning - new stage in the foreign language teaching. Procedia - Social and Behavioural Sciences, 197, 1957-1961. https://doi.org/10.1016/j.sbspro.2015.07.582.

[15] Hubackova, S., \& Semradova, I. (2016). Evaluation of blended learning. Procedia - Social and Behavioural Sciences, 217, 551-557. https:// doi.org/10.1016/j.sbspro.2016.02.044.

[16] Hwang, G. Y., Yin, C., \& Chu, H. C. (2019).The era of flipped learning: Promoting active learning and higher order thinking with innovative flipped learning strategies and supporting 
systems. Interactive Learning Environments, 27(8), 991-994. https://doi.org/10.1080/1049482 0.2019 .1667150 .

[17] Ismaili, Y. (2021). Evaluation of students' attitude toward distance learning during the pandemic (COVID-19): A case study of ELTE university. On the Horizon. https:/ / doi.org/10.1108/ OTH-09-2020-0032.

[18] Klimova, B. F., \& Kacetl, J. (2015). Hybrid learning and its current role in the teaching of foreign languages. Procedia - Social and Behavioural Sciences,182, 477-481.https://doi.org/10.1016/j. sbspro.2015.04.830.

[19] Koşar, G. (2016). A Study of EFL instructors' perception of blended learning. Procedia - Social and Behavioural Sciences, 232, 736-744. https://doi.org/10.1016/j.sbspro.2016.10.100.

[20] Lai, C., \& Li, G. (2011). Technology and task-based language teaching: A critical review. CALICO Journal, 28(2), 498-521.

[21] Luka, I. (Ed). (2018). B1/B2 English language course curriculum. Retrieved May 6, 2021, from http://e-culture.eu/wp-content/uploads/2020/03/B1_B2_English_curriculum.pdf.

[22] Luka, I. (2019). Creating a culture-based language learning course for developing adult learners' 21st century skills. Journal of Education Culture and Society, 10(2), 151-169, https://doi. org/10.15503/jecs20192.151.169.

[23] Lungu, I. (2013). The increasing need for blended-learning models in courses of English for Specific Courses in Romanian universities. Procedia - Social and Behavioural Sciences, 76, 470475. https:// doi.org/10.1016/j.sbspro.2013.04.148.

[24] MacIntyre, P., Gregersen, T., \& Mercer, S. (2020). Language teachers' coping strategies during the Covid-19 conversion to online teaching: Correlations with stress,wellbeing and negative emotions. System, 94, Article 102352, 1-13. https:/ / doi.org/10.1016/j.system.2020.102352.

[25] Matukhin, D., \& Zhitkova, E. (2015). Implementing Blended Learning Technology in Higher Professional Education. Procedia - Social and Behavioural Sciences, 206, 183-188. https://doi. org/10.1016/j.sbspro.2015.10.051.

[26] Maulam, S. M., \& Ibrahim, R. (2012). The teaching and learning of English for Academic Purposes in blended learning. Procedia - Social and Behavioural Sciences, 67, 561-570. https://doi. org/10.1016/j.sbspro.2012.11.361.

[27] Miyazoe, T., \& Anderson, T. (2012). Discuss, reflect, and collaborate: A qualitative analysis of forum, blog, and wiki use in EFL blended learning course. Procedia - Social and Behavioural Sciences, 34, 146-152. https:// doi.org/10.1016/j.sbspro.2012.02.030.

[28] O'Hanlon, F. (2019). Mixed-methods research: Achieving a robust design. In: L. Hamilton, \& J. Ravenscroft (Eds.), Building research design in education (pp. 107-131). London: Bloomsbury Academy.

[29] Ossiannilsson, E. (2016). Challenges and opportunities for active and hybrid learning related to UNESCO Post 2015. In: J. Keengwe \& G. Onchwari (Eds.), Handbook of research on active learning and the flipped classroom model in the digital age (pp. 333-351). USA: IGI Global.

[30] Prokhorets, E. K., Plekhanova, M. V., \& Scherbinina, N. G. (2015). Instructional Designof Foreign Language Blended Courses. Procedia - Social and Behavioural Sciences, 215, 161-169. https://doi.org/10.1016/j.sbspro.2015.11.611.

[31] Raes, A., Detienne, L., Windey, I., \& Depaepe F. (2020). A systematic literature review on synchronous hybrid learning: gaps identified. Learning Environments Research, 23, 269-290. https://doi.org/10.1007/s10984-019-09303-z.

[32] Rasheed, R. A., Kamsin, A., \& Abdullah, N. A. (2020). Challenges in the online component of blended learning: A systematic review. Computers \& Education, 144, Article 103701, 1-17. https://doi.org/10.1016/j.compedu.2019.103701.

[33] Rodrigues, H., Almeida, F., Figueiredo, V., \& Lopes, S. L. (2019). Tracking e-learning through published papers: A systematic review. Computers and Education, 136, 87-98. https://doi. org/10.1016/j.compedu.2019.03.007.

[34] Šafranj, J. (2013). Using information technology in english language learning procedure: Blended learning. Procedia - Social and Behavioural Sciences, 83, 514-521. https://doi. org/10.1016/j.sbspro.2013.06.099.

[35] Thomas, G. (2009). How to do your research project. London: SAGE.

[36] Tosun, S. (2015). The effects of blended learning on EFL students' vocabulary enhancement. Procedia - Social and Behavioural Sciences, 199, 641-647. https://doi.org/10.1016/j. 
sbspro.2015.07.592.

[37] Tymms, P. (2017). Questionnaires. In: R. Coe, M. Waring, L.V. Hedges \& J. Arthur (Eds.), Research methods \& methodologies in education (pp. 223-233). Los Angeles: Sage.

[38] UNESCO. (2021a). Supporting learning recovery: One year into COVID-19. The Global Education Coalition in Action, March 2021. Retrieved May 7, 2021, from https:/ / unesdoc.unesco.org/ ark:/48223/pf0000376061/PDF/376061eng.pdf.multi.

[39] UNESCO. (2021b). One year into COVID: Prioritizing education recovery to avoid a generational catastrophe. Report of UNESCO online conference on 29 March 2021. Retrieved May 4, 2021, from https://unesdoc.unesco.org/ark:/48223/pf0000376984/PDF/376984eng.pdf. multi.

[40] Zitter, I., \& Hoeve, A. (2012). Hybrid learning environments: Merging learning and work processes to facilitate knowledge integration and transitions. OECD Education Working Papers, 81. http://dx.doi.org/10.1787/5k97785xwdvf-en. 